\title{
Comunicação
}

[Communication]

\section{Perfil citológico dos líquidos amniótico e alantoidiano nos terços inicial, médio e final da gestação na vaca}

\author{
[Cytology of amniotic and allantoic fluids in the cow at the first, second, and third \\ trimester of pregnancy]
}

\author{
M.R.P. Moura $^{1}$, L.L. Lanna ${ }^{1}$, A.P. Marques Júnior ${ }^{2}$ \\ ${ }^{1}$ Aluna de pós-graduação - EV-UFMG - Belo Horizonte, MG \\ ${ }^{2}$ Escola de Veterinária - UFMG - Belo Horizonte, MG
}

Apesar da importância da espécie bovina para a pecuária brasileira e para o desenvolvimento de novas tecnologias na área de biotecnologia da reprodução, pesquisas que envolvem conhecimento mais amplo sobre os líquidos extraembrionários ainda são escassas. Os fluidos amniótico e alantoidiano são componentes importantes para a gestação normal da vaca. Sua produção e absorção dependem de uma série de fatores que interferem na interrelação entre a mãe e o feto via placenta, além de fatores ambientais. Seu volume e composição variam de acordo com o estádio da gestação (Constant et al., 2006), e entre suas funções estão atuar no crescimento do feto e na barreira contra infecções, proteger contra traumatismos, auxiliar no controle da temperatura fetal e na livre movimentação do feto, prevenir a aderência entre o feto e o âmnio e auxiliar no momento do parto. No terço final da gestação, a composição dos líquidos amniótico e alantoidiano difere substancialmente uma da outra, assim como da urina fetal e do plasma materno e fetal (Wintour et al., 1986).

Com o advento de novas tecnologias, como transferência de embriões (TE), fertilização in vitro (FIV) e transferência nuclear (TN), pode ocorrer aumento no acúmulo de líquidos fetais. Vacas gestantes de fetos de TN mostram acentuada acumulação anormal de líquidos fetais, principalmente hidroalantoide, com aumento da mortalidade fetal no terço médio da gestação, ou de fetos que apresentam alta incidência da síndrome do feto grande, hidroalantoide e placentomegalia no terço final da gestação (Li et al., 2005; Constant et al., 2006). Falhas na gestação de TN poderiam estar associadas ao desenvolvimento anormal da placenta, que afetam principalmente o trofoblasto nos estádios iniciais da placentação, sugerindo que proteínas específicas são importantes para esclarecer as aberrações encontradas (Hashizume et al., 2002). Evidências da expressão de aquaporina na membrana fetal humana foram encontradas em células amnióticas in vitro (Wang et al., 2006). Na gestação com polidroâmnio, a expressão de aquaporina-1 está aumentada, sugerindo que alterações na sua expressão podem estar associadas a essa patologia (Mann et al., 2006).

O objetivo deste trabalho foi descrever o perfil citológico dos líquidos amniótico e alantoidiano da vaca.

Foram utilizados 30 úteros de vacas gestantes, obtidos em frigoríficos, de animais mestiços Holandês/Zebu, classificadas em três grupos (G) de 10 animais cada, de acordo com o estádio de gestação. O G1 foi formado por animais no terço inicial (0 a 90 dias), o G2, no terço médio (90 a 180 dias), e o G3, no terço final (180 a 280 dias) da gestação. Para o cálculo do estádio gestacional, foi medido o comprimento apicocaudal, segundo Richardson (1989).

De cada espécime, foram coletados $20 \mathrm{~mL}$ de líquido alantoidiano e amniótico, com seringa e agulha, e $10 \mathrm{~mL}$ de cada líquido, sem coagulante,

Recebido em 3 de novembro de 2008

Aceito em 15 de setembro de 2009

E-mail: mariaraquel.moura@gmail.com 
foram centrifugados por 10 minutos a $200 \mathrm{~g}$. Dos sedimentos de cada alíquota, foram feitos esfregaços, os quais foram corados pelo método panótico rápido ${ }^{1}$, para contagem e avaliação da citologia. Foram contados 40 campos aleatórios por lâmina e consideradas: células eosinifílicas nucleadas e anucleadas, células cianofílicas nucleadas e anucleadas e células orangeofílicas.

No terço inicial da gestação (G1), a média do tamanho do concepto foi de $13,5 \mathrm{~cm}$ de comprimento apicocaudal, o que corresponde, aproximadamente, a 86,25 dias de gestação; no terço médio (G2), a média foi de $29,25 \mathrm{~cm}$, ou 125,62 dias de gestação, e no terço final (G3), a média foi de $63,77 \mathrm{~cm}$, ou 211,92 dias de gestação.

Nos achados macroscópicos, o líquido amniótico caracterizou-se fisicamente como claro, incolor e mucoide, porém mais viscoso com o adiantamento da gestação, semelhante ao relatado por Arthur et al. (1996) e Hafez (2004). $\mathrm{O}$ líquido alantoidiano caracterizou-se fisicamente como aquoso e âmbar, com seu volume maior que o do amniótico nos três terços gestacionais, aumentando essa relação com o adiantado da gestação, semelhante aos achados de Roberts (1986), Arthur et al. (1996) e Hafez (2004). Não foi possível identificar células no líquido alantoidiano.

Os resultados (Tab. 1) mostram variações significativas entre o terço inicial, médio e final da gestação da vaca, nas médias das células eosinofílicas nucleadas e nas células cianofílicas anucleadas. Essas diferenças foram evidenciadas entre o terço inicial e final da gestação, nas células totais e nas células cianofílicas nucleadas. Nas células eosinofílicas anucleadas e orangeofílicas, não houve diferença significativa entre os estádios de gestação.

Bongso e Basrur (1977), ao utilizarem o método de coloração Papanicolau, descreveram com detalhes as células eosinofílicas nucleadas e anucleadas, cianofílicas nucleadas e anucleadas e as células orangeofílicas. Neste trabalho, a coloração pelo panótico rápido mostrou-se eficiente para identificar as células do líquido amniótico com base nas suas características morfológicas, exceto as células orangeofílicas. Desse modo, o método panótico rápido mostrouse eficiente para o acompanhamento da citologia do líquido amniótico na vaca mestiça Holandês/Zebu.

Tabela 1. Média do número de células totais, eosinofílicas com e sem núcleo, cianofílicas com e sem núcleo e orangeofílicas, do líquido amniótico dos terços inicial (G1), médio (G2) e final (G3) da gestação da vaca

\begin{tabular}{ccccccc}
\hline $\mathrm{G}$ & Cel Totais & EosinCN & EosinSN & CianofCN & CianofSN & Orangeof \\
\hline 1 & $16,38 \pm 4,17 \mathrm{a}$ & $7,25 \pm 5,47 \mathrm{a}$ & $3,13 \pm 4,09 \mathrm{a}$ & $1,13 \pm 1,55 \mathrm{a}$ & $1,00 \pm 1,07 \mathrm{a}$ & $4,25 \pm 3,49 \mathrm{a}$ \\
2 & $94,13 \pm 55,15 \mathrm{~b}$ & $25,63 \pm 11,20 \mathrm{~b}$ & $8,25 \pm 8,66 \mathrm{a}$ & $43,50 \pm 57,14 \mathrm{~b}$ & $11,38 \pm 10,23 \mathrm{~b}$ & $5,38 \pm 4,27 \mathrm{a}$ \\
3 & $125,1 \pm 52,45 \mathrm{~b}$ & $48,78 \pm 23,71 \mathrm{c}$ & $8,67 \pm 8,69 \mathrm{a}$ & $32,11 \pm 16,06 \mathrm{~b}$ & $31,78 \pm 22,48 \mathrm{c}$ & $2,22 \pm 6,67 \mathrm{a}$ \\
\hline
\end{tabular}

Letras distintas, na mesma coluna, indicam diferença significativa entre os valores $(\mathrm{P}<0,05)$.

Palavras-chave: vaca, citologia, placenta, fluidos fetais

\begin{abstract}
The cytology of extraembrionic fluids in cows in the first, second, and third trimester of pregnancy was evaluated. For each trimester, 10 pregnant uteri, collected in the slaughterhouse were used. A volume of $20 \mathrm{~mL}$ of amniotic and allantoic fluids was collected, and centrifuged at $200 \mathrm{~g}$ for 10 minutes. The sediment was taken and processed on a slide for cytology examination after staining. The results showed that the total cells number of the amniotic fluid increased during gestation, with the panoptic staining method being efficient to evaluate the amniotic fluid cytology in crossbreed Holstein $x$ Zebu cows.
\end{abstract}

Keywords: cow, cytology, placenta, fetal fluids

${ }^{1}$ Panótico Rápido - LaborClin, Curitiba, Brasil. 


\section{REFERÊNCIAS BIBLIOGRÁFICAS}

ARTHUR, G.H.; NOAKES, D.E.; PEARSON, H. et al. (Ed). Veterinary reproduction obstetrics. 7.ed. London: Saunders, 1996. 726p.

BONGSO, T.A.; BASRUR, P.K. Cytology of bovine fetal fluids. Can. J. Comp. Med., v.41, p.287-293, 1977.

CONSTANT, F.; GUILLOMOT, M.; HEYMAN, Y. et al. Large offspring or large placenta syndrome? Morphometric analysis of late gestation bovine placentomes from somatic nuclear transfer pregnancies complicated by hidrallantois. Biol. Reprod., v.75, p.122-130, 2006.

HAFEZ, B.; HAFEZ, E.S.E. Reprodução Animal. 7.ed. Barueri: Manole, 2004. 513p.

HASHIZUME, K.; ISHIWATA, H.; KISAKI, K. et al. Implantation and placental development somatic cell clone recipient cows. Cloning Stem Cells, v.4, p.197-209, 2002.

LI, N.; WELLS, D.N.; PETERSON, A.J. et al. Perturbations in the biochemical composition of fetal fluids are apparent in surviving bovine somatic cell nuclear transfer pregnancies in the first half of gestation. Biol. Reprod., v.73, p.139$148,2005$.
MANN, S.E.; DVORAK, N.; GILBERT, H. et al. Steady-state levels of aquaporin-1 mRNA expression are increase in idiopathic polyhydroâmnio. Am. J. Obstet. Gynecol., v.194, p.884-887, 2006.

RICHARDSON, C. Personal communication In: ARTHUR, G.H.; NOAKES, D.E.; PEARSON, H. Veterinary reproduction and obstetrics. 6.ed. London: Baillière Tindall, 1989. p.49-59.

ROBERTS, S.J. Veterinary obstetrics and genital diseases. 3.ed. Ann Harbor: Edwards Brothers, 1986. 981p.

WANG, S.; ANIDI, F.; BEALL, M. et al. Aquaporin-3 expression in human fetal membranes and its up-regulation by cyclic adenosine monophosphate in âmnio epithelial cell culture. J. Soc. Gynecol. Investig., v.13, p.181-185, 2006.

WINTOUR, E.M.; LARENCE, B.M.; LINGWOOD, B.E. Anatomy, physiology and pathology of the amniotic and allantoic compartments in sheep and cow. Austr. Vet. J., v.63, p.216-221, 1986. 